\title{
Interleukin-2 Receptor (Tac Antigen) Expressed on Adult T Cell Leukemia Cells
}

Takashi Uchiyama, Toshiyuki Hori, Mitsuru Tsudo, Yuji Wano, Hiroshi Umadome, Shigeki Tamori, Junji Yodoi, Michiyuki Maeda, Hiroyasu Sawami, and Haruto Uchino

The First Division of Internal Medicine, Institute for Immunology, Faculty of Medicine, Chest Disease Research Institute, Kyoto University, Kyoto 606 Japan; Department of Internal Medicine, Kansai Denryoku Hospital, Osaka, Japan

\section{Abstract}

We studied the expression of the interleukin-2 (IL-2) receptor and the proliferative response to exogenous IL-2 of peripheral blood leukemic cells from patients with adult $T$ cell leukemia (ATL) in order to see whether IL-2 receptor expressed on ATL cells is different from normal IL-2 receptor and whether it plays a role in the neoplastic growth in ATL.

Peripheral blood leukemic cells from 42 patients with ATL examined expressed IL-2 receptors that were detected by antiTac monoclonal antibody when examined immediately after the separation of cells or after the culture for 24 or $48 \mathrm{~h}$. The number of anti-Tac binding sites ranged from 3,100 to 11,400 in fresh cells and from 3,600 to $96,000 /$ cell in short-term cultured leukemic cells, whereas phytohemagglutinin-P (PHAP)-stimulated normal $T$ cells exhibited 6,900-35,000 anti-Tac binding sites per cell. ATL-derived and human T cell leukemia/ lymphoma virus, type I (HTLV-I)-infected cell lines such as MT-1 and Hut102 expressed a much higher number of antiTac binding sites.

Leukemic cells from 15 patients with ATL examined showed no or very poor proliferative response to various concentrations of immunoaffinity-purified IL-2, although they expressed Tac antigen (Ag). Radiolabeled IL-2 binding experiments demonstrated that ATL leukemic cells could bind IL2, and they expressed both high and low affinity IL-2 receptors, although the number of high affinity IL-2 receptor was much less than that of low affinity IL-2 receptor and that of antiTac binding sites.

In contrast, leukemic $\mathbf{T}$ cells from a patient with $\mathbf{T}$ cell chronic lymphocytic leukemia (CLL), in whom HTLV-I infection was not demonstrated, responded as well as PHA-Pstimulated normal $T$ cells, and their IL-2 receptors, unlike ATL cells, were modulated (down regulated) by anti-Tac antibody.

No differences were noted between ATL cells and normal activated $T$ cells in one-dimensional sodium dodecyl sulfate polyacrylamide gel electrophoresis analysis of the $I L-2$ receptor. Thus, leukemic cells in ATL spontaneously and continuously express IL-2 receptor, which appears to be abnormally regulated and unresponsive to IL-2. These results, taken together with those on normal IL-2 receptors on HTLV-I-negative T-CLL cells, suggest that abnormal expression of the IL-2 receptor in

Address correspondence to Dr. Uchiyama, Kyoto University.

Received for publication 14 September 1984 and in revised form 23 April 1985.

J. Clin. Invest.

(C) The American Society for Clinical Investigation, Inc.

0021-9738/85/08/0446/08 \$1.00

Volume 76, August 1985, 446-453
ATL is closely associated with HTLV-I infection and may play a role in the neoplastic growth of ATL cells.

\section{Introduction}

Adult T cell leukemia (ATL), ${ }^{1}$ which has characteristic clinical and hematologic features and is endemic southwest of Japan (1-3), is a leukemia of peripheral, mature, and OKT4(+) T cells (4). Studies subsequent to the discovery and isolation of a novel human retrovirus, human $\mathrm{T}$ cell leukemia/lymphoma virus, type I (HTLV-I) $(5,6)$, have demonstrated a close association between HTLV-I and the leukemogenesis of ATL (7-10), although the mechanism of the cell transformation that may be induced by HTLV-I infection remains unclear.

We previously reported that leukemic cells in ATL are derived from peripheral mature $T$ cells with a helper/inducer subset phenotype and express Tac antigen ( $\mathrm{Ag}$ ) (interleukin-2 [IL-2] receptor) (4) that is recognized by anti-Tac monoclonal antibody (11-13). Popovic et al. (14) also noted the strong expression of $\mathrm{Tac} \mathrm{Ag}$ on cord blood cells that were transformed by co-culturing with HTLV-producing cell lines. A recent report by Waldmann et al. also showed that HTLV-positive ATL cells, but not HTLV-negative Sézary cells, express IL-2 receptors (15). In addition, we found that $\mathrm{Tac} \mathrm{Ag}$ on $\mathrm{ATL}$ cells, unlike those on normal activated $\mathrm{T}$ cells, is not modulated by anti-Tac antibody (16), which suggests the abnormal regulation of Tac Ag expression in ATL cells. The proliferation of normal peripheral $T$ cells initiated by antigen or lectin is mediated by IL-2, which is produced by activated $T$ cells and binds to inducible IL-2 receptors. Further characterization of the IL-2 receptor on ATL cells is needed to understand whether it is merely a marker of ATL cells or if it is involved in their neoplastic growth.

In the present study, we examined the molecular size and IL-2 binding activity of IL-2 receptors expressed on peripheral blood leukemic cells from patients with ATL, and the proliferative response of ATL cells to exogenous IL-2, comparing those of normal activated T cells and HTLV-I negative leukemic $T$ cells.

We will show that peripheral blood leukemic $T$ cells in ATL respond very poorly to exogenous IL-2, although they express Tac antigen of similar molecular weight to that of normal activated $T$ cells and can bind IL-2. In contrast, leukemic $T$ cells from a patient with chronic lymphocytic

1. Abbreviations used in this paper: ADF, ATL-derived factor; Ag, antigen, ATL, adult T cell leukemia; FCS, fetal calf serum; HTLV-I, human T cell leukemia/lymphoma virus (type I); IL-2, interleukin-2; PHA-P, phytohemagglutinin-P; SDS-PAGE, sodium dodecyl sulfate polyacrylamide gel electrophoresis; T-CLL, T cell chronic lymphocytic leukemia. 
leukemia which were negative for HTLV-I provirus integration, expressed Tac antigen and showed a good proliferative response to IL-2.

\section{Methods}

Patient population. 42 patients with ATL and one patient with chronic lymphocytic leukemia of T cell origin were studied. The age of ATL patients ranged from 24 to 76 , and 25 of the 42 patients were male. The diagnosis of ATL was made on the basis of clinical features (2), hematologic characteristics (2), serum antibodies to ATL-associated antigens (6) in all cases, and the HTLV provirus integration in DNA of leukemic cells in seven cases. Peripheral white blood cell count ranged from 15,900 to $249,000 / \mathrm{mm}^{3}$.

The patient with $\mathrm{T}$ cell chronic lymphocytic leukemia (T-CLL) was a 54-yr-old male with generalized lymph node enlargement and a high white blood cell count (range, 29,200-100,000 cells $/ \mathrm{mm}^{3}$ ). Peripheral blood smears showed lymphoid cells with nonconvoluted nuclei.

Cell separation and culture. Peripheral blood mononuclear cells were separated from heparinized blood by Ficoll-Hypaque density gradient centrifugation. Both fresh leukemic cells and frozen cells, which had been stored in liquid nitrogen, were used. The recovered cells with good viability ( $>85 \%$ ) were used. More than $80 \%$ of the cells in the cell suspension examined were leukemic cells as determined by the morphological characteristics of cells on the May-Giemsa-stained slides.

Leukemic cells cultured from 1 to $7 \mathrm{~d}$ in RPMI 1640 medium containing $10 \%$ fetal calf serum (FCS) (M.A. Bioproducts, Walkersville, MD) or autologous serum or plasma were also examined for the expression and IL-2 binding of IL-2 receptor. Normal peripheral blood mononuclear cells cultured with $0.1 \%$ phytohemagglutinin-P (PHA-P) (Difco Laboratories, Detroit, MI) for 2-7 d were used for the quantitation of Tac antigen and for IL-2 binding assay. ATL-derived and HTLVI-infected cell lines, MT-1 (17) and Hut102 (18), which were maintained with RPMI 1640 medium (Nissui Pharmaceutical Co., Ltd., Tokyo, Japan) containing $10 \%$ FCS, were also used.

Detection of $I L-2$ receptor by immunofluorescence. Anti-Tac monoclonal antibody that recognizes human IL-2 receptor (13) was used to detect IL-2 receptor. Its production and characterization were described elsewhere $(11,13)$. One-million cells were incubated with a saturating amount of anti-Tac antibody at $4^{\circ} \mathrm{C}$ for $30 \mathrm{~min}$, washed twice with Hanks' balanced salt solution containing $0.1 \%$ bovine serum albumin and $0.1 \%$ sodium azide, and then incubated with fluorescein isothiocyanate-conjugated $\mathrm{F}(\mathrm{ab})_{2}$ anti-mouse IgG (Cappel Laboratories, Cochranville, PA) at $4^{\circ} \mathrm{C}$ for $30 \mathrm{~min}$. Control staining was performed with normal BALB/c mouse serum instead of anti-Tac antibody. Washed and resuspended cells were observed under a fluorescence microscope, or subjected to flow cytofluorometric analysis using a FACS analyzer (Becton-Dickinson \& Co, FACS Systems, Sunnyvale, CA) or a Spectrum III (Ortho Diagnostic Systems, Westwood, MA).

Radiolabeled anti-Tac binding assay. Anti-Tac antibody purified by gel and DEAE cellulose chromatography from hybridoma ascites was radiolabeled by the chloramine $T$ method (specific activity 5,600$16,000 \mathrm{cpm} / \mathrm{ng}$ ). Bindable fraction of radiolabeled anti-Tac was $\sim 90 \%$ of all activity when determined by the binding of radiolabeled antiTac to an excess number of cells. $50 \mu \mathrm{l}$ of serial dilutions of ${ }^{125} \mathrm{I}$-antiTac, $50 \mu \mathrm{l}$ of medium, and $400 \mu \mathrm{l}$ of cell suspension $\left(1.0-4.0 \times 10^{6} \%\right.$ $\mathrm{ml}$ ) in RPMI 1640 medium containing 2\% FCS were mixed and incubated on ice for $30 \mathrm{~min}$. After washing and resuspending cells in $500 \mu \mathrm{l}$ of medium, $200 \mu \mathrm{l}$ of the cell suspension in duplicate was centrifuged through a $150-\mu$ l layer of a mixture of $20 \%$ olive oil (Nakarai Chemicals, Kyoto, Japan) and $80 \%$ Di- $n$-butyl phthalate (Nakarai Chemicals). The tips of the tubes containing the cell pellet were cut off and the radioactivity was counted in a gamma counter. Nonspecific binding was estimated by incubating cells with both radiolabeled anti-Tac and $>1,000$-fold excess amount of unlabeled
anti-Tac. Nonspecific binding was $<3.7 \%$ of total activities bound to cells in these experiments. Specific binding was obtained by subtracting nonspecific binding. To obtain accurate values of bound/free antibody, the values were corrected for bindable proportion of total radioactivity. Scatchard analysis of binding assay was performed by plotting values of bound/free vs. bound anti-Tac antibody.

Radiolabeled IL-2 binding assay. Escherichia coli-derived recombinant IL-2 was kindly provided by Takeda Chemical Industries Inc. (Osaka, Japan). The purity of recombinant IL-2 was $>99.8 \%$, and the biological activity which was comparable to Jurkat cell line-derived immunoaffinity-purified IL-2 was determined by the proliferation assay using IL-2-dependent cell lines and PHA-P-stimulated normal peripheral blood lymphocytes (data not shown). IL-2 was radiolabeled using ${ }^{125} \mathrm{I}-\mathrm{Bolton}$ and Hunter's reagents (B\&H reagent, $2,000 \mathrm{Ci} / \mathrm{mmol}$, monoiodinated, NEX-120, New England Nuclear, Boston, MA). Specific radioactivity of labeled IL-2 was $2,000-5,000 \mathrm{cpm} / \mathrm{ng}$. Effective radioactivity bindable to cells was $\sim 90 \%$ of the total activity.

Radiolabeled IL-2 binding assay was performed according to the method described by Robb et al. $(19,20)$ with a slight modification. Cells were incubated at $37^{\circ} \mathrm{C}$ in IL-2-free fresh RPMI 1640 medium twice for $60 \mathrm{~min}$ to promote dissociation and/or degradation of endogenously bound IL-2. Serial dilutions of radiolabeled IL-2 and 2$5 \times 10^{6}$ cells in a total volume of $0.5 \mathrm{ml}$ of RPMI 1640 medium containing $25 \mathrm{mM}$ Hepes, pH 7.2, and $10 \mathrm{mg} / \mathrm{ml}$ of bovine serum albumin (Armour Pharmaceutical Co., Kankakee, IL) were incubated at $37^{\circ} \mathrm{C}$ for $60 \mathrm{~min}$. After incubating, washing, and resuspending cells, $200 \mu \mathrm{l}$ of cell suspension in duplicate was centrifuged through a 150$\mu l$ layer of a mixture of $20 \%$ olive oil and $80 \%$ Di-n-butyl phthalate. The tips of the tubes containing the cell pellet were cut off and the radioactivity was counted in a gamma counter. Nonsaturable binding was determined by incubating cells with 250 -fold excess amount of unlabeled IL-2. Specific binding was obtained by subtracting nonsaturable binding. The number of IL-2 binding sites and the affinity was estimated by Scatchard analysis.

Proliferative response to $I L-2$. Normal peripheral blood mononuclear cells cultured with $0.1 \%$ PHA-P for $7 \mathrm{~d}$ and peripheral blood leukemic cells were studied for the proliferative response to IL-2. One-tenth of a million cells were placed in a 96-well microtiter plate (Falcon Labware, Oxnard, CA) and cultured in $200 \mu$ l of RPMI 1640 medium containing $10 \%$ FCS and $30 \mu \mathrm{g} / \mathrm{ml}$ of gentamicin in the presence of various concentrations of immunoaffinity-purified IL-2 (reference 19, generously provided by Dr. K. Smith; $1 \mathrm{U}$ biological activity $=8.2 \mathrm{ng}$ protein) at $37^{\circ} \mathrm{C}$ in a humid atmosphere with $5 \% \mathrm{CO}_{2}$ for $72 \mathrm{~h}$. The cultured cells were pulsed with $\left[{ }^{3} \mathrm{H}\right]$ thymidine $(2 \mathrm{Ci} / \mathrm{mol}$, Amersham Corp., Arlington Heights, IL) for the last $6 \mathrm{~h}$, followed by precipitation onto glass fiber filters, and the radioactivity was counted by liquid scintillation. MT-1 cells were cultured both at $5 \times 10^{4} / \mathrm{ml}$ and 2.5 $\times 10^{5}$ cells $/ \mathrm{ml}$ in a 96-well plate in the presence of IL-2.

Sodium dodecyl sulfate polyacrylamide gel electrophoresis (SDS$P A G E$ ). Tac Ag immunoprecipitated by anti-Tac antibody from labeled cell lysates was analyzed by one-dimensional SDS-PAGE according to the method described in detail previously (21). In brief, leukemic cells from ATL patients (viability, $>90 \%$ ) were surface labeled with $\left[{ }^{125} \mathrm{I}\right] \mathrm{Na}$ (New England Nuclear) by the lactoperoxidase method, washed and lysed in a cell extraction buffer $(0.5 \%$ Nonidet $\mathrm{P}-40,10 \mathrm{mM}$ Tris- $\mathrm{HCl}$, $0.15 \mathrm{M} \mathrm{NaCl}, 1 \mathrm{mM}$ phenylmethylsulfonyl fluoride, $\mathrm{pH}$ 7.2). Tac antigen was immunoprecipitated from labeled cell lysates by incubation with anti-Tac antibody and staphylococcal protein A-coupled Sepharose 4B (Pharmacia Fine Chemicals, Piscataway, NJ). The immunoprecipitate was electrophoresed on $7.5 \%$ polyacrylamide gel and visualized by autoradiography.

\section{Results}

Expression of $I L-2$ receptor (Tac $A g$ ) on $A T L$ leukemic cells. Peripheral blood leukemic cells from 32 of the 42 patients with ATL examined expressed IL-2 receptors (Tac Ag) on 
their cell surface when stained with anti-Tac antibody and examined immediately after separation of cells. $9-60 \%$ of the fresh cells examined were reactive with anti-Tac antibody in these 32 patients. Less than $5 \%$ of the fresh cells from the remaining 10 patients were reactive with anti-Tac antibody. Leukemic cells from these 10 patients, however, expressed the receptor when examined after 24 or $48 \mathrm{~h}$ culture in medium containing $10 \%$ FCS or autologous serum or plasma. $20-60 \%$ of short-term cultured leukemic cells were reactive with antiTac antibody. Leukemic cells cultured with medium generally expressed more IL-2 receptors on their cell surface than did fresh cells (Fig. 1). In case M.S., the number of anti-Tac binding sites was 5,500/cell on fresh leukemic cells and 96,000/ cell on leukemic cells cultured for $5 \mathrm{~d}$. In other words, 17-fold increase in the number of Tac Ag sites was detected after $5 \mathrm{~d}$ of culture. Cytofluorometric studies performed at the same time also revealed a marked increase of fluorescence intensity (Fig. 1).

In contrast, fresh peripheral blood lymphocytes from 20 normal individuals did not express IL- 2 receptor ( $<2 \%$ of the cells were reactive with anti-Tac). Furthermore, only a small proportion $(2.9-5.1 \%)$ of normal lymphocytes cultured with medium containing 10\% FCS for $48 \mathrm{~h}$ expressed Tac antigen as detected by immunofluorescence method. Radiolabeled anti-Tac binding assay of short-term (48 h) cultured normal peripheral blood lymphocytes demonstrated 500-890 (mean $730, n=4$ ) anti-Tac binding sites per cell, which were much less than those of short-term cultured leukemic cells from ATL patients (Table I).

Radiolabeled anti-Tac antibody binding. The specificity of radiolabeled anti-Tac antibody binding was studied by the binding inhibition in the presence of an excess amount of unlabeled anti-Tac, IL-2, OKT3 antibody, and OKIal antibody. More than $96 \%$ of radiolabeled anti-Tac binding to PHA-Pstimulated normal lymphocytes or Hut 102 cells was inhibited
Day 0

Case MS

Case KI

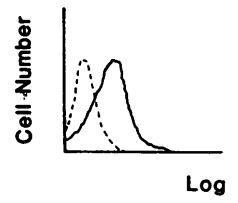

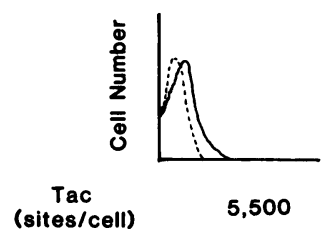

Day 2

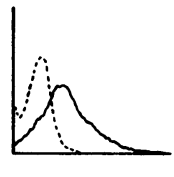

11,000

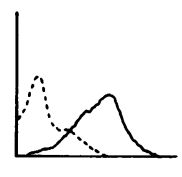

Fluorescence
Day 5

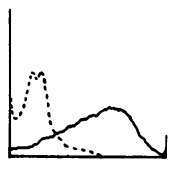

96,000
Figure 1. Enhanced expression of IL-2 receptor (Tac Ag) on ATL cells after a short-term culture. Peripheral blood leukemic cells from two patients with ATL were stained with anti-Tac antibody after separation from blood or after culture with medium alone for 2 or 5 d, and then examined by flow cytofluorometry. Dotted lines indicate control staining with normal mouse serum instead of anti-Tac antibody. Anti-Tac binding sites were determined by Scatchard analysis after binding assay using radiolabeled anti-Tac. by the presence of $>1,000$-fold excess amount of unlabeled anti-Tac. In addition, $\sim 98 \%$ of radiolabeled anti-Tac binding was inhibited by excess IL-2. OKT3 and OKIal antibodies, however, did not inhibit $(<5 \%)$ radiolabeled anti-Tac binding. The reversibility of radiolabeled anti-Tac binding was tested by adding an excess amount of unlabeled anti-Tac to Hut 102 cells that had been incubated by radiolabeled anti-Tac. $58 \%$ of the bound anti-Tac was released after $120 \mathrm{~min}$ incubation at $37^{\circ} \mathrm{C}$.

Fig. 2 shows a typical binding curve and a Scatchard plot of radiolabeled anti-Tac binding study of $5 \mathrm{~d}$ cultured ATL leukemic cells. The number of anti-Tac binding sites per cell on leukemic cells from ATL patients, HTLV-I-infected cell lines, PHA-P-stimulated T cells, and leukemic cells from a patient with T-CLL is shown in Table $I$. In patient M.S., leukemic cells were examined for anti-Tac binding on several occasions in his clinical course. HTLV-I-infected cell lines, MT-1 and Hut102, expressed a high number of Tac Ag sites $(560,000$ and 410,000 sites/cell, respectively). Fresh peripheral blood leukemic cells from ATL patients expressed 3,10011,400/cell anti-Tac binding sites. More Tac Ag molecules were detected when leukemic cells were examined after cultured for 5 or $6 \mathrm{~d}$, although the increase varied in each case. Peripheral blood $\mathrm{T}$ cells usually expressed the maximal number of anti-Tac binding sites after 2 to $3 \mathrm{~d}$ of activation with PHA$P$, which declined thereafter. In seven normal subjects, 6,90035,000 Tac Ag sites per cell were detected on $\mathrm{T}$ cells cultured in the presence of PHA-P for 2-7 d. The affinity of anti-Tac binding in ATL cells and HTLV-I-infected cell lines $\left(K_{\mathrm{a}}=4\right.$ $7 \times 10^{9} \mathrm{M}^{-1}$ ) was not different from that of PHA-P-stimulated normal lymphocytes.

Peripheral blood leukemic $\mathrm{T}$ cells from a patient with $\mathrm{T}$ CLL expressed 2,000 anti-Tac binding sites per cell. HTLV-I provirus integration in DNA of leukemic cells was not demonstrated by the Southern blot hybridization method (Fukui, K., and T. Honjo, unpublished data) and no serum antibody to ATL-associated antigens was detected in this patient (data not shown).

Proliferative response of leukemic cells from ATL patients to $I L-2$. Peripheral blood T cells from 10 normal individuals who had been cultured for $7 \mathrm{~d}$ in the presence of $0.1 \%$ PHA$P$ responded well to added immunoaffinity-purified IL-2 (Fig. 3). On the contrary, fresh leukemic cells from 11 ATL patients and cryopreserved leukemic cells from 4 ATL patients which expressed $\mathrm{Tac} \mathrm{Ag}$ did not respond well to various concentrations of IL-2. The stimulation index $\left(\left[{ }^{3} \mathrm{H}\right]\right.$ thymidine uptake cultured with IL-2/[ $\left.{ }^{3} \mathrm{H}\right]$ thymidine uptake cultured with medium alone) at an IL-2 concentration of $0.5 \mathrm{U} / \mathrm{ml}$ ranged from 0.2 to 6.5 in ATL leukemic cells and from 75 to 806 in PHA-Pstimulated normal T cells. MT-1 cells established from an ATL patient (17) did not respond to IL-2 in spite of the markedly enhanced expression of $\mathrm{Tac} \mathrm{Ag}$ (Fig. 4, Table 1). Leukemic cells from a patient with T-CLL, on the other hand, showed a good proliferative response to IL-2, which was comparable with that of PHA-P-stimulated normal $T$ cells (Fig. 4).

We also studied ATL cells cultured for 3-7 d, which expressed more IL-2 receptors than fresh leukemic cells in order to assess whether their poor proliferative response of ATL leukemic cells were due to an inadequate number of IL2 receptors on fresh leukemic cells. Cultured leukemic cells, 


\begin{tabular}{|c|c|c|c|c|c|}
\hline & & \multicolumn{2}{|c|}{ Anti-Tac (sites per cell) } & \multicolumn{2}{|c|}{ IL-2 (sites per cell) } \\
\hline & & Fresh & Cultured & High affinity & Low affinity \\
\hline \multirow[t]{8}{*}{$\mathrm{ATL}^{*}$} & Case M.S. & 5,500 & 96,000 & & \\
\hline & & & 42,000 & & \\
\hline & & & 32,000 & 2,300 & Not determined \\
\hline & & 4,400 & 34,000 & 2,100 & 37,500 \\
\hline & S.M. & 4,300 & 13,000 & & \\
\hline & F.K. & 5,100 & 6,100 & & \\
\hline & Y.O. & 11,400 & 15,000 & 960 & Not determined \\
\hline & K.U. & 3,100 & 3,600 & & \\
\hline HTLV-I-infected & MT-1 & & 560,000 & & \\
\hline cell lines & Hut 102 & & 410,000 & 3,300 & 330,000 \\
\hline T-CLL (case O.O.) & & 2,000 & & & \\
\hline \multicolumn{6}{|l|}{ Normal lymphocytes } \\
\hline \multicolumn{6}{|c|}{ Cultured with medium for: } \\
\hline $2 \mathrm{~d}($ mean, $n=4)$ & & & 730 & & \\
\hline \multicolumn{6}{|c|}{ Stimulated by PHA-P for: } \\
\hline $2 \mathrm{~d}($ mean, $n=2)$ & & & 23,000 & 2,700 & 23,000 \\
\hline $3 \mathrm{~d}($ mean, $n=3)$ & & & 35,000 & 3,500 & 25,500 \\
\hline $7 \mathrm{~d}($ mean, $n=2)$ & & & 6,900 & 1,300 & 8,000 \\
\hline
\end{tabular}

The number of anti-Tac and IL-2 binding sites were determined by Scatchard analysis of radiolabeled anti-Tac and radiolabeled IL-2 binding experiments. * Peripheral blood leukemic cells from ATL patients were examined both after separated from blood or recovered from freshfrozen state and after cultured for 3-6 d.

however, still showed a poor response to exogenous IL-2 even after the number of cell surface anti-Tac binding sites increased (data not shown). In addition, peripheral blood leukemic cells from three patients with ATL who were examined did not respond to IL-2 even at a concentration of $32 \mathrm{U} / \mathrm{ml}$ (two patients) or $130 \mathrm{U} / \mathrm{ml}$ (one patient).

Radiolabeled IL-2 binding. Unstimulated normal peripheral

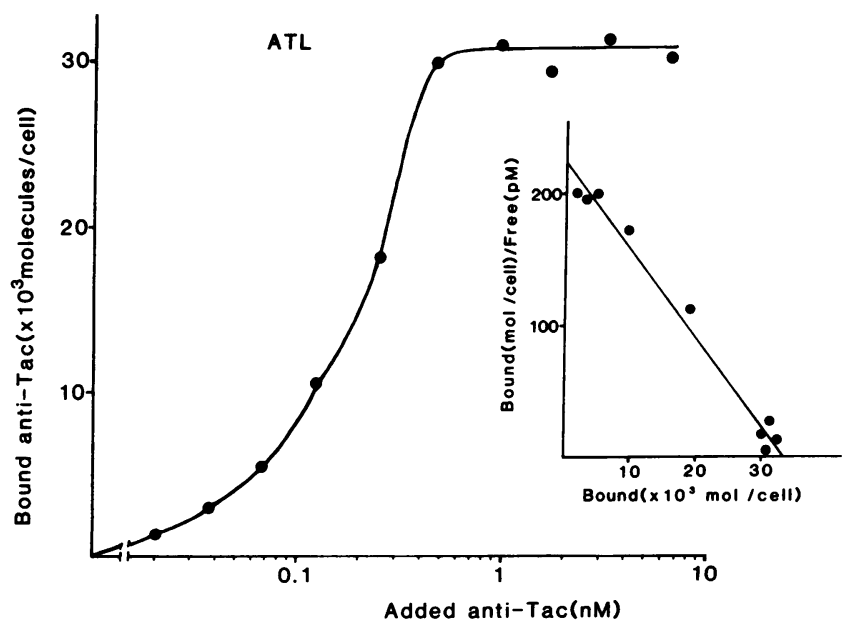

Figure 2. Radiolabeled anti-Tac binding to ATL leukemic cells cultured for $5 \mathrm{~d}$. The data shown were obtained by subtracting nonspecific binding, which was estimated by incubating cells with an excess amount of unlabeled anti-Tac. The result was transformed into a Scatchard plot which is shown in an inset. The calculated number of binding sites was $34,000 /$ cell and $K_{\mathrm{a}}=6.6 \times 10^{9} \mathrm{M}^{-1}$ in this experiment. blood lymphocytes and Tac-negative $\mathrm{T}$ or $\mathrm{B}$ cell lines did not bind significant amount of radiolabeled IL-2 (data not shown). As radiolabeled anti-Tac binding, the reversibility of radiola-

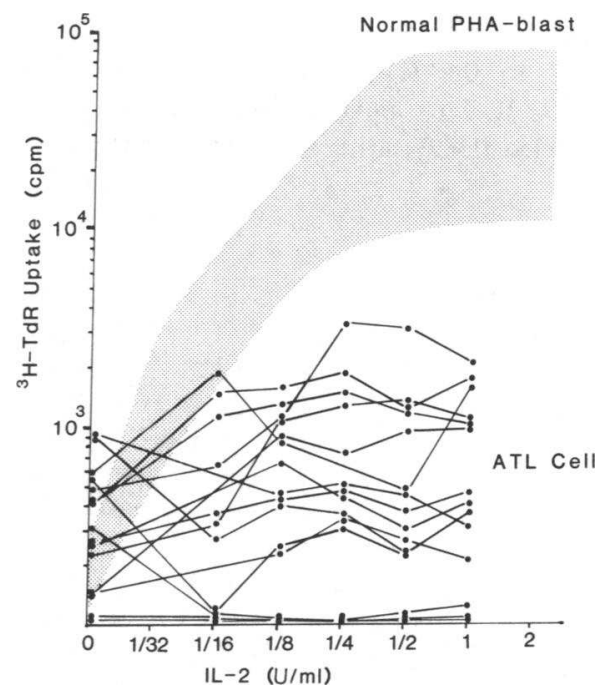

Figure 3. Proliferative response to IL-2 of peripheral blood leukemic cells from 15 patients with ATL. Leukemic cells were cultured with various concentrations of immunoaffinity-purified IL-2 for $72 \mathrm{~h}$ and $\left[{ }^{3} \mathrm{H}\right]$ thymidine uptake was determined. Each point represents mean of triplicate culture. Proliferative response to IL-2 of peripheral blood lymphocytes from 10 normal individuals cultured with 0.1\% PHA-P for $7 \mathrm{~d}$ is shown as the shaded area. The leukemic cells from 15 ATL patients examined showed no or very poor proliferative response to IL-2 as compared with PHA-P-stimulated normal lymphocytes. TdR, thymidine. 


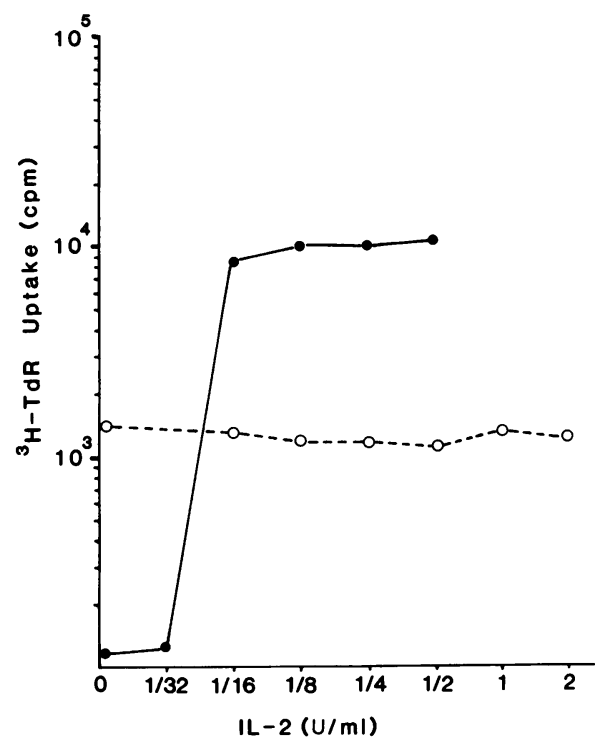

Figure 4. Proliferative response to IL-2 of HTLV-I-uninfected leukemic cells from a patient with T-CLL and ATL-derived, HTLV-Iinfected MT-1 cell line. Peripheral blood leukemic cells from the TCLL patient and MT-1 cells were cultured with various concentrations of IL-2 for $72 \mathrm{~h}$ and $\left[{ }^{3} \mathrm{H}\right]$ thymidine uptake was determined. Each point represents mean of triplicate culture. The result shown is a representative of three different experiments. Leukemic cells from the T-CLL patient showed a good proliferative response comparable to that seen in PHA-P-stimulated normal lymphocytes, whereas MT1 cells did not respond to IL-2. $\bullet$, T-CLL; O, MT-1, TdR, thymidine.

beled IL-2 binding was studied. The reversible proportion of the binding was $\sim 90 \%$ of the total activity bound to the cells.

In order to determine whether no or very poor proliferative response of ATL leukemic cells to exogenous IL-2 was due to poor binding of IL-2 to the IL-2 receptor, we tested the binding of radiolabeled IL-2 to leukemic cells. As shown in Figs. 5 and 6, radiolabeled IL-2 binding assay and its Scatchard

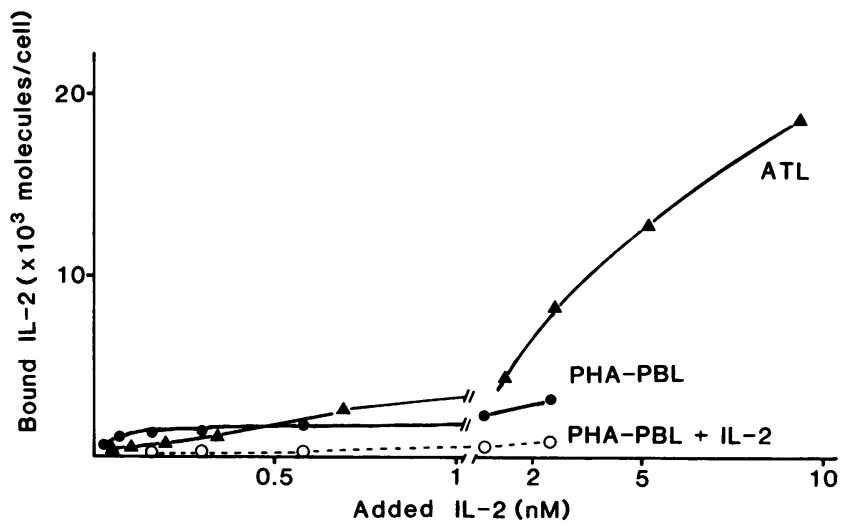

Figure 5. Radiolabeled IL-2 binding to normal peripheral blood lymphocytes cultured in the presence of $0.1 \%$ PHA-P for $7 \mathrm{~d}$ (PHAPBL) and to 5-d-cultured ATL leukemic cells obtained from patient M.S. Nonsaturable binding was determined by incubating cells with 250-fold excess amount of unlabeled IL2. Nonsaturable binding curve of only the PHA-P-stimulated cells (PHA-PBL + IL-2) is shown in this figure. Binding curves for ATL leukemic cells (ATL) and PHA-P-stimulated lymphocytes (PHA-PBL) are specific binding curves which were obtained by subtracting unsaturable binding.

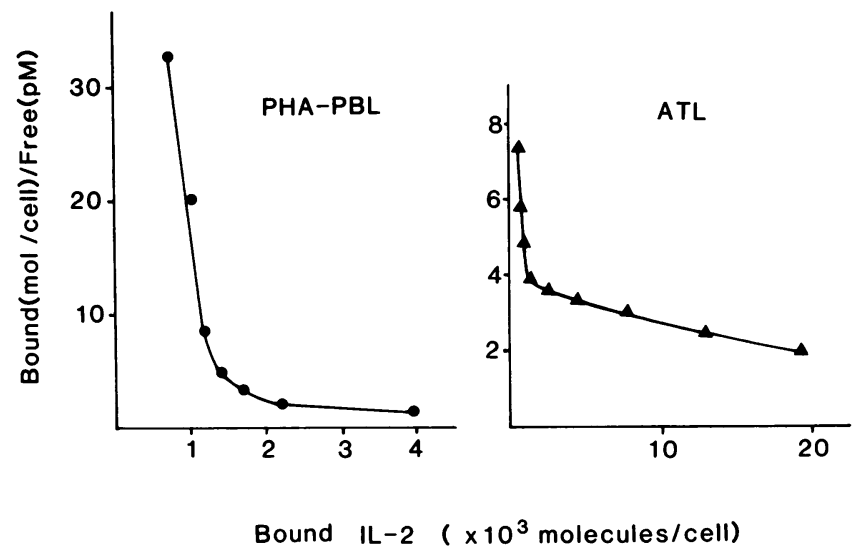

Figure 6. A Scatchard plot of radiolabeled IL-2 binding data shown in Fig. 5. The results indicate that there are two different classes of IL-2 receptors with two different affinities. Calculated high and low affinity receptor numbers are 1,300 and 8,000/cell in PHA-PBL, and 2,100 and 37,500/cell in ATL leukemic cells, respectively. The affinities obtained from Scatchard analysis of both high and low affinity receptors are $K_{\mathrm{a}}=6.9 \times 10^{10} \mathrm{M}^{-1}, 8.8 \times 10^{8} \mathrm{M}^{-1}$ in PHA-PBL, and $K_{\mathrm{a}}=1.1 \times 10^{10} \mathrm{M}^{-1}, 9.5 \times 10^{8} \mathrm{M}^{-1}$ in ATL leukemic cells, respectively. PHA-PBL, PHA-stimulated lymphocytes.

analysis demonstrated IL-2 receptors with two different affinities in PHA-P-stimulated normal peripheral lymphocytes, HTLVI-infected cell lines (data not shown), and leukemic cells from ATL patients. Peripheral blood lymphocytes stimulated by PHA-P for 2-7 d exhibited 1,300-3,500 IL-2 receptors/cell with high affinity $\left(K_{\mathrm{a}}=2.6-6.9 \times 10^{10} \mathrm{M}^{-1}\right)$ and 8,000-25,500 receptors/cell with low affinity $\left(K_{\mathrm{a}}=3.7-8.8 \times 10^{8} \mathrm{M}^{-1}\right)$. In Hut 102 cells, the majority of IL-2 receptors were low affinity receptors. In ATL case M.S., fresh leukemic cells expressed $250 /$ cell high and 2,250/cell low affinity IL-2 receptors. The leukemic cells cultured with medium for $5 \mathrm{~d}$ expressed 2,100/ cell high and 37,500/cell low affinity IL-2 receptors, the total of which was roughly equal to the number of anti-Tac binding sites $(34,000 /$ cell). Radiolabeled IL-2 binding assay of both fresh and short-term cultured leukemic cells from another ATL patient (case S.Y.) also showed both low and high affinity IL-2 receptors (data not shown), as in case M.S. No major differences were noted in the affinity of two classes of IL-2 receptors between ATL leukemic cells $\left(K_{\mathrm{a}}=1.1 \times 10^{10} \mathrm{M}^{-1}\right.$, $\left.9.5 \times 10^{8} \mathrm{M}^{-1}\right)$, Hut 102 cells, and PHA-P-stimulated normal lymphocytes.

These radiolabeled IL-2 binding experiments showed that both ATL leukemic cells and HTLV-I-infected cell lines expressed comparable number of high affinity IL-2 receptors to that of PHA-P-stimulated normal lymphocytes, which could bind IL-2 at the concentrations used in the proliferative response to IL-2, and also expressed a large number of low affinity IL-2 receptors.

Polyacrylamide gel analysis of $I L-2$ receptor on $A T L$ leukemic cells. IL-2 receptors expressed on the surface of leukemic cells from five ATL patients were analyzed on onedimensional PAGE. No difference was observed among IL-2 receptors expressed on ATL leukemic cells, ATL-derived MT1 cell line, and PHA-P-activated normal T cells (Fig. 7). Apparent molecular weight of IL-2 receptors on ATL leukemic cells estimated on polyacrylamide gel was $60,000-65,000$. 


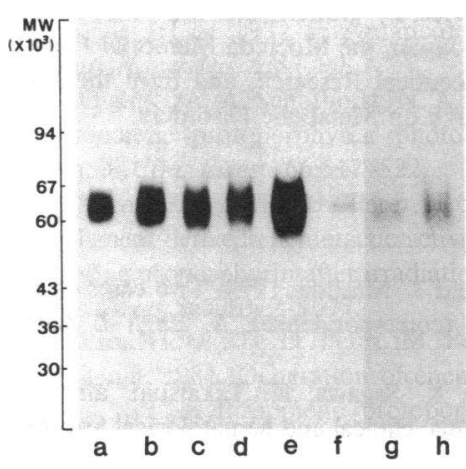

Figure 7. One-dimensional SDS-PAGE analysis of IL-2 receptor ( $\mathrm{Tac} \mathbf{A g}$ ) expressed on leukemic cells from five patients with ATL. The cell surface of the leukemic cells was radiolabeled by the lactoperoxidase method. Cell lysate of iodinated cells was immunoprecipitated by anti-Tac antibody and analyzed by SDS-PAGE. (a) PHA-Pstimulated normal T cells;

(b) ATL-derived MT-1 cell; $(c-g)$ fresh peripheral blood leukemic cells from five patients with ATL; $(h)$ leukemic cells cultured with medium for $2 \mathrm{~d}$ from the same patient as $g$. In all cases of ATL examined and MT-1 cell line, one band with an apparent molecular weight of $60,000-65,000$ was detected; it was identical to that seen in PHA-P-stimulated T cells.

\section{Discussion}

In the present study we showed that peripheral blood leukemic cells from patients with ATL express IL-2 receptor on their cell surface in the absence of known activators such as lectin, or antigens that induce IL-2 receptor on normal resting $T$ cells. ATL leukemic cells, however, respond very poorly to exogenous IL-2, although they express a comparable or higher number of IL- 2 receptors as detected by anti-Tac antibody and radiolabeled IL- 2 binding experiments. They can bind radiolabeled IL-2, and their IL-2 receptors are not different from those on normal activated $T$ cells, as determined by PAGE.

It is most unlikely that the majority of $\mathrm{Tac} \mathrm{Ag}$-positive cells detected by the immunofluorescence and flow cytometric analysis were contaminated normal lymphocytes because the majority of the cells stained and examined were leukemic cells and few Tac Ag-positive cells were detected in both fresh and short-term cultured normal peripheral blood lymphocytes. Demonstration of the IL-2 receptor on peripheral blood leukemic cells from 42 ATL patients examined in the present study, together with our previous findings $(4,16)$ and those of others $(14,15)$, clearly shows that leukemic $T$ cells infected with HTLV-I express IL-2 receptors. HTLV-I-infected cultured cell lines such as MT-1 and Hut102 especially express an augmented number of IL-2 receptors (12-21-fold more than PHA-P-stimulated T cells), as detected by binding assay using radiolabeled anti-Tac. HTLV-I infection is not always required for leukemic $T$ cells to spontaneously express IL-2 receptors, as we detected IL-2 receptor on leukemic $T$ cells from a $T$ CLL patient in which HTLV-I provirus integration into DNA of leukemic cells was not demonstrated. Nevertheless, it is likely that HTLV-I infection, directly or indirectly, induces enhanced IL-2 receptor expression, the mechanism of which remains to be clarified.

The mechanism underlying the increase of $I L-2$ receptor expression of leukemic cells from ATL patients during a shortterm culture remains unclear. It seems unlikely that this increase is due to the removal of the factor(s) which may be contained in the serum or plasma and inhibit the expression of IL-2 receptors in vivo, because the increase of IL-2 receptor expression was also observed when leukemic cells were cultured with medium containing autologous serum or plasma. Teshigawara et al. (22) have recently reported that HTLV-I-infected cell lines produce a factor termed ATL-derived factor (ADF), which augments IL-2 receptor expression. ADF may be produced by ATL leukemic cells during a short-term culture and may contribute to the increase of IL-2 receptor expression. Using complementary DNA encoding human IL-2 receptor, we are trying to study the change of the quantity of IL-2 receptor mRNA of ATL cells during the culture in order to determine whether the increase in the number of $I L-2$ receptors is due to the actual enhancement of $\mathrm{IL}-2$ receptor synthesis and whether ADF or ADF-like factors are involved in the enhancement of IL-2 receptor expression.

The initial finding of the very poor proliferative response of ATL leukemic cells was unexpected, because many cultured cell lines with HTLV-I provirus integration were established by culturing leukemic cells with IL-2 $(14,23)$. Our results, however, suggested that cultured cell lines from ATL patients were derived from residual nonleukemic $T$ cells that were infected with HTLV-I and could respond to added IL-2. The recent report (24) analyzing the HTLV-I provirus integration site indicated that the populations of infected cells of fresh and long-term cultured cell lines from the same patient appeared to be different.

It is unlikely that the poor proliferative response of ATL leukemic cells to exogenous IL-2 is due to a small number of IL-2 receptors on fresh leukemic cells, because ATL leukemic cells bearing comparable or higher number of both high and low affinity IL-2 receptors after a short-term culture still remained unresponsive to $>10$-fold excess concentration of IL-2, which can saturate high affinity IL-2 receptors. Leukemic $T$ cells from a patient with T-CLL also responded well to IL2 in spite of the lower number of IL-2 receptors on the cell surface. In addition, MT-1 and Hut 102 cells, derived from ATL patients, did not respond to IL-2 although they expressed 50-80-fold higher number of IL-2 receptors. A similar phenomenon was reported in the A431 cell line (25). These cells derived from epidermoid carcinoma cells and, expressing a large number of epidermal growth factor receptors, do not respond to ordinary concentrations of epidermal growth factor $(26,27)$.

Radiolabeled IL-2 binding experiments and PAGE analysis were performed to determine whether the poor proliferative response to IL-2 is due to the alteration of the IL-2 receptor molecule or to changes in its binding capacity. Certain HTLVI-infected cell lines have been found to express aberrant IL-2 receptors when examined by PAGE (21). However, onedimensional PAGE analysis disclosed no difference between normal IL-2 receptors and those on leukemic cells from five ATL patients examined and several HTLV-I-infected cell lines including MT-1, indicating a normal IL-2 receptor molecule on ATL cells, although we cannot exclude the possibility that the subtle changes in the IL-2 receptor molecules, undetectable by PAGE analysis, may exist in ATL cells. Precise comparative chemical characterization, including amino acid sequence determination using c-DNA of the IL-2 receptor, which both we and others have succeeded in cloning $(28,29)$, will answer this question.

Radiolabeled IL-2 binding experiments showed that ATL leukemic cells with poor proliferative responsiveness to exog- 
enous IL-2 expressed both high and low affinity IL-2 receptors, and no major differences were noted between their affinities and those of PHA-P-stimulated normal lymphocytes. The total number of low and high affinity IL-2 receptors was roughly equal to that of anti-Tac binding sites in the present studies, which was consistent with the results reported by Robb et al. (20). The results obtained from the proliferative response studies, PAGE analysis, and radiolabeled IL-2 binding experiments strongly suggested that the poor proliferative response of ATL leukemic cells to exogenous IL-2 is due to the abnormality of the events which are initiated by the IL-2 binding to IL-2 receptors, and eventually lead to the cell growth in normal activated $\mathrm{T}$ cells.

We previously reported the abnormal regulation of $\mathrm{Tac} \mathrm{Ag}$ on ATL leukemic cells (16). In addition, the IL-2 receptor on ATL-derived and HTLV-I-infected MT-1 cell line is spontaneously phosphorylated, whereas IL-2 receptor on PHA-stimulated normal $\mathrm{T}$ cells is IL-2-dependently phosphorylated (Wano, Y., T. Uchiyama, N. Kobayoshi, M. Hatanaka, M. Maeda, J. Yodoi, and H. Uchino, submitted for publication). Taken together, leukemic cells in ATL spontaneously and continuously express an enhanced number of IL-2 receptors that appear abnormally regulated, unresponsive to IL-2, and IL-2-independently phosphorylated.

In contrast, leukemic $T$ cells from a $T$-CLL patient in which HTLV infection was not demonstrated expressed IL-2 receptors, proliferated in response to purified IL-2, and their IL-2 receptor was modulated (down regulated) by anti-Tac antibody as normal IL-2 receptor on activated T cells (data not shown). These results suggest the close association between the abnormal expression of the IL-2 receptor and HTLV-I infection in ATL.

Several aspects of abnormally expressed IL-2 receptors in ATL leukemic cells previously reported (16) and demonstrated in the present study suggest that spontaneously, continuously, and unregulatably expressed IL-2 receptors may be responsible for the uncontrollable growth of ATL cells (30). The autocrine hypothesis, in which IL-2 continuously produced by HTLVI-infected mature $T$ cells is considered to mediate the neoplastic growth by binding to IL-2 receptors induced on their own cell surface (31), has been ruled out because of the lack of IL-2 gene expression in HTLV-I-infected cells (32). In ATL, IL-2 receptors that are abnormally regulated, unresponsive to IL-2, and spontaneously (IL-2 independently) phosphorylated, may continuously generate growth signals that lead to the neoplastic growth of ATL cells. Recent studies demonstrating the structural and functional similarities between growth factor molecules or their receptors and oncogene products $(33,34)$ suggest the involvement of uncontrolled production of growth factors or uncontrolled receptor functions in the cell transformation. Further studies are required to clarify the mechanism of the IL-2 receptor expression in relation to HTLV-I infection, and to demonstrate directly the role of the IL-2 receptor in the proliferation of leukemic cells in ATL.

\section{Acknowledgments}

The authors are grateful to Dr. Kendall A. Smith, Dartmouth Medical School, Hanover, NY, for the kind gift of an immunoaffinity-purified IL-2, to Takeda Chemical Industries, Ltd. (Osaka, Japan) for recombinant IL-2, to Dr. I. Miyoshi, Kochi Medical School, Kochi, Japan, for MT-1 cells, and to Dr. R. C. Gallo, National Cancer Institute, Bethesda, MD, for Hut 102 cells.
This work was partly supported by grants from the Ministry of Education, Science and Culture, Japan, the Mochida Memorial Foundation for Medical and Pharmaceutical Research, and from the Yamanouchi Foundation for Research on Metabolic Disorders.

\section{References}

1. Yodoi, J., K. Takatsuki, and T. Masuda. 1974. Two cases of Tcell chronic leukemia in Japan (correspondence). N. Engl. J. Med. 290:572.

2. Uchiyama, T., J. Yodoi, K. Sagawa, K. Takatsuki, and H. Uchino. 1977. Adult T-cell leukemia: clinical and hematological features of 16 cases. Blood. 50:481-492.

3. Takatsuki, K., T. Uchiyama, K. Sagawa, and J. Yodoi. 1977. Adult T cell leukemia in Japan. In Topics in Hematology. S. Seno, F. Takaku, and S. Irino, editors. Excerpta Medica, Amsterdam. 73-77.

4. Hattori, T., T. Uchiyama, T. Toibana, T. Takatsuki, and H. Uchino. 1981. Surface phenotype of Japanese adult T-cell leukemia cells characterized by monoclonal antibodies. Blood. 58:645-647.

5. Poiesz, B. J., F. W. Ruscetti, A. F. Gazdar, P. A. Bunn, J. D. Minna, and R. C. Gallo. 1980. Detection and isolation of type-C retrovirus particles from fresh and cultured lymphocytes of a patient with cutaneous T-cell lymphoma. Proc. Natl. Acad. Sci. USA. 77: 7415-7419.

6. Hinuma, Y., K. Nagata, M. Hanaoka, M. Nakai, T. Matsumoto, K. Kinoshita, S. Shirakawa, and I. Miyoshi. 1981. Adult T-cell leukemia: antigen in an ATL cell line and detection of antibodies to the antigen in human sera. Proc. Natl. Acad. Sci. USA. 78:6476-6480.

7. Robert-Guroff, M., Y. Nakao, K. Notake, Y. Ito, A. Sliski, and R. C. Gallo. 1982. Natural antibodies to human retrovirus HTLV in a culture of Japanese patients with adult T cell leukemia. Science (Wash. DC). 215:975-978.

8. Hinuma, Y., H. Komoda, T. Chosa, T. Kondo, M. Kohakura, T. Takenaka, M. Kikuchi, M. Ichimaru, K. Yunoki, I. Sato, R. Matsuo, Y. Takiuchi, H. Uchino, and M. Hanaoka. 1982. Antibodies to adult T-cell leukemia virus-associated antigen (ATLA) in sera from patients with ATL and controls in Japan: a nationwide seroepidemiologic study. Int. J. Cancer. 29:631-635.

9. Yoshida, Y., I. Miyoshi, and Y. Hinuma. 1982. Isolation and characterization of retrovirus (ATLV) from cell lines of adult T-cell leukemia and its implication in the disease. Proc. Natl. Acad. Sci. USA. 79:2031-2035.

10. Blattner, W. A., V. S. Kalyanaraman, M. Robert-Guroff, T. A. Listner, D. A. G. Galton, P. S. Sarin, M. H. Crawford, D. Catovsky, M. Greaves, and R. C. Gallo. 1982. The human type-C retrovirus, HTLV, in blacks from the Caribbean region and relationship to adult T-cell leukemia/lymphoma. Int. J. Cancer. 30:257-264.

11. Uchiyama, T., S. Broder, and T. A. Waldmann. 1981. A monoclonal antibody (anti-Tac) reactive with activated and functionally mature human T cells. I. Production of anti-Tac monoclonal antibody and distribution of Tac(+) cells. J. Immunol. 126:1393-1397.

12. Uchiyama, T., D. L. Nelson, T. A. Fleisher, and T. A. Waldmann. 1981. A monoclonal antibody (anti-Tac) reactive with activated and functionally mature human $\mathrm{T}$ cells. II. Expression of Tac antigen on activated cytotoxic $T$ cells, suppressor cells and on one of two types of helper T cells. J. Immunol. 126:1398-1403.

13. Leonard, W. J., M. Depper, T. Uchiyama, K. A. Smith, T. A. Waldmann, and W. C. Greene. 1982. A monoclonal antibody that appears to recognize the receptor for human T-cell growth factor: partial characterization of the receptor. Nature (Lond.). 300:267-269.

14. Popovic, M., G. Lange-Wantzin, P. S. Sarin, D. Mann, and R. C. Gallo. 1983. Transformation of human umbilical cord blood T cells by human T-cell leukemia/lymphoma virus. Proc. Natl. Acad. Sci. USA. 80:5402-5406.

15. Waldmann, T. A., W. C. Greene, P. S. Sarin, C. Saxinger, D. W. Blayney, W. A. Blattner, C. K. Goldman, K. Bongiovanni, S. Sharrow, J. M. Depper, W. Leonard, T. Uchiyama, and R. C. Gallo. 
1984. Functional and phenotypic comparison of human T cell leukemia/ lymphoma virus, positive adult $T$ cell leukemia with human $T$ cell leukemia/lymphoma virus, negative Sezary leukemia, and their distinction using anti-Tac monoclonal antibody identifying the human receptor for T cell growth factor. J. Clin. Invest. 73:1711-1718.

16. Tsudo, M., T. Uchiyama, H. Uchino, and J. Yodoi. 1983. Failure of regulation of Tac antigen/TCGF receptor on adult $T$ cell leukemia cells by anti-Tac monoclonal antibody. Blood. 61:10141016.

17. Miyoshi, I., I. Kubonishi, M. Sumida, S. Yoshimoto, S. Hiraki, T. Tsubota, H. Kobashi, M. Lay, T. Tanaka, I. Kimura, K. Miyamoto, and J. Sato. 1979. Characteristics of a leukemic T-cell line derived from adult T-cell leukemia. Jpn. J. Clin. Oncol. 9(Suppl):485-494.

18. Gazdar, A. F., D. N. Carney, P. A. Bunn, E. K. Russell, E. S. Jaffe, G. P. Schechter, and J. G. Guccion. 1980. Mitogen requirements for the in vitro propagation of cutaneous T-cell lymphomas. Blood. 55:409-417.

19. Robb, R. J., A. Munck, and K. A. Smith. 1981. T cell growth factor receptors. Quantitation, specificity, and biological relevance. $J$. Exp. Med. 154:1455-1474.

20. Robb, R. J., W. C. Greene, and C. M. Rusk. 1984. Low and high affinity cellular receptors for interleukin-2. Implications for the level of Tac antigen. J. Exp. Med. 160:1126-1146.

21. Wano, Y., T. Uchiyama, M. Maeda, K. Fukui, H. Uchino, and J. Yodoi. 1984. Characterization of human interleukin 2 receptor (Tac antigen) in normal and leukemic $T$ cells: co-expression of normal and aberrant receptors on Hut 102 cells. J. Immunol. 132:3005-3010.

22. Teshigawara, K., M. Maeda, K. Nishino, T. Nikaido, T. Uchiyama, M. Tsudo, Y. Wano, and J. Yodoi. 1985. Adult T cell leukemia cells produce a lymphokine that augments interleukin 2 receptor expression. J. Mol. Cell. Immunol. 2:17-22.

23. Hoshino, H., H. Esumi, M. Miwa, M. Shimoyama, K. Minato, K. Tobinai, M. Hirose, S. Watanabe, N. Inada, K. Kinoshita, S. Kamihira, M. Ichimaru, and T. Sugimura. 1983. Establishment and characterization of 10 cell lines derived from patients with adult $\mathrm{T}$ cell leukemia. Proc. Natl. Acad. Sci. USA. 80:6961-6065.

24. Hahn, B., R. C. Gallo, G. Franchini, M. Popovic, T. Aoki, S. Z. Salahuddin, P. D. Markham, and F. Wong-Staal. 1984. Clonal selection of human T-cell leukemia virus-infected cells in vivo and in vitro. Mol. Biol. Med. 2:29-36.

25. Gill, G., and C. S. Lazar. 1981. Increased phosphotyrosine content and inhibition of proliferation in EGF-treated A431 cells. Nature (Lond.). 293:305-307.

26. Barnes, D. W. 1982. Epidermal growth factor inhibits growth of A431 human epidermoid carcinoma in serum-free cell culture. $J$. Cell Biol. 93:1-4.

27. Fabricant, R. N., J. E. DeLarco, and G. J. Todaro. 1977. Nerve growth factor receptors on human melanoma cells in culture. Proc. Natl. Acad. Sci. USA. 74:565-569.

28. Nikaido, T., A. Shimizu, N. Ishida, H. Sabe, K. Teshigawara, M. Maeda, T. Uchiyama, J. Yodoi, and T. Honjo. 1984. Molecular cloning of cDNA encoding human interleukin 2 receptor. Nature (Lond.). 311:631-635.

29. Leonard, W. J., J. M. Depper, G. R. Crabtree, S. Rudikoff, J. Pumphery, R. J. Robb, M. Kronke, P. B. Svetlik, N. C. Peffer, T. A. Waldmann, and W. C. Greene. 1984. Molecular cloning and expression of cDNAs for the human interleukin-2 receptor: evidence for alternate mRNA splicing and the use of two polyadenylation sites. Nature (Lond.). 311:626-631.

30. Yodoi, J., T. Uchiyama, and M. Maeda. 1983. T cell growth factor receptor in adult $\mathrm{T}$ cell leukemia (correspondence). Blood. 62: 509-510.

31. Gallo, R. C., and F. Wong-Staal. 1982. Retroviruses as etiologic agents of some animal and human leukemias and lymphomas and tools for elucidating the molecular mechanism of leukemogenesis. Blood. 60:545-557.

32. Arya, S. K., F. Wong-Staal, and R. C. Gallo. 1984. T-cell growth factor gene: lack of expression in human T-cell leukemialymphoma virus-infected cells. Science (Wash. DC). 223:1086-1087.

33. Waterfield, M. D., T. Scrace, N. Whittle, P. Stroobant, A. Johnsson, A. Wasteson, B. Westermark, C. H. Heldin, J. S. Huang, and T. F. Devel. 1983. Platelet-derived growth factor is structurally related to the putative transforming protein P28sis of simian sarcoma virus. Nature (Lond.). 304:35-39.

34. Downward, J., Y. Yarden, E. Mayes, G. Scrace, N. Totty, P. Stockwell, A. Ullrich, J. Schlessinger, and M. D. Waterfield. 1984. Close similarity of epidermal growth factor receptor and v-erb-B oncogene protein sequences. Nature (Lond.). 307:521-527. 